\title{
Optimal Battery Sizing of a Grid-Connected Residential Photovoltaic System for Cost Minimization using PSO Algorithm
}

\author{
Nibaruta Regis \\ Department of Electrical \\ Engineering, PAU Institute of Basic \\ Sciences, Technology and \\ Innovation, Nairobi, Kenya \\ nibaregis@gmail.com
}

\author{
Christopher Maina Muriithi \\ School of Engineering and \\ Technology \\ Murang'a University of Technology \\ Nairobi, Kenya \\ cmmuriithi@mut.ac.ke
}

\author{
Livingstone Ngoo \\ Faculty of Engineering and \\ Technology \\ Multimedia University of Kenya \\ Nairobi, Kenya \\ livingngoo@gmail.com
}

\begin{abstract}
This paper proposes a new optimization technique that uses Particle Swarm Optimization (PSO) in residential gridconnected photovoltaic systems. The optimization technique targets the sizing of the battery storage system. With the liberation of power systems, the residential grid-connected photovoltaic system can supply power to the grid during peak hours or charge the battery during non-peak hours for later domestic use or for selling back to the grid during peak hours. However, this can only be achieved when the battery energy system in the residential photovoltaic system is optimized. The developed PSO algorithm aims at optimizing the battery capacity that will lower the operation cost of the system. The computational efficiency of the developed algorithm is demonstrated using real PV data from Strathmore University. A comparative study of a PV system with and without battery energy storage is carried out and the simulation results demonstrate that PV system with battery is more efficient when optimized with PSO.
\end{abstract}

Keywords-grid-connected PV; electricity surplus; sizing; battery energy storage; electricity prices; net metering; PSO

\section{INTRODUCTION}

Nowadays electricity access plays a vital role and governments and private sector are investing in the electricity domain to ensure sustainable development. Climate change and the relaxation of the electric energy market boosted the development of renewable energy integration in electric grids [1]. In many developing countries the reliable access to electricity is still a big challenge. Grids are sometimes marked by limited supply and prevailing disruptions. Due to this, some electricity users who especially own classical grid-connected PV systems do not derive a benefit from their installations considering the intermittent nature of the solar panel [2]. The hours of high PV production do not necessarily coincide with peak load demand hours. Since customers usually experience frequent undesirable power cuts, it is possible that this issue will grow in the future. It is very important to look at alternative ways of minimizing the operational cost of a gridtied PV system. One of the alternatives is integrating optimally sized energy storages into a grid-connected PV system.
There have been various contributions towards cost minimization and energy storage optimization where different approaches have been investigated. Authors in [3, 4] used Dynamic Programing (DP), whereas in $[5,6]$ the optimization was performed by means of Markov Decision processes and Fuzzy Clustering Method. Authors in [7], presented an economic analysis of a PV system under a net-metering scheme. Due to the randomness of Renewable Energy Sources (RES) and the serial characteristic of the decision problem in the analysis, a metaheuristic approach is preferred. Whilst analytical methods usually endure some problems like slow convergence and dimensionality, metaheuristic-based optimizations are much more effective in handling large-scale nonlinear optimization problems. In [8], a genetic algorithm was developed to optimally size lead acid batteries that run under dynamic pricing strategies in both independent and aggregated ways. Authors in [9] introduced a PSO-based algorithm for optimally sizing constituents of a hybrid renewable system, aiming to maximize the energy production to cover the load at lowest cost and enhanced reliability. An improved firefly algorithm was proposed in [10] to optimally locate and size the battery energy storage system for mitigating the voltage rise in PVDG integrated distribution network. Authors in [11] proposed a two layer optimization procedure using PSO to optimize the battery size of a grid-tied PV system. Authors in [12] conducted a comparative study between DP and PSO for solving unit commitment problems. Authors in [13] proposed a mechanism for minimizing the operation cost of a grid-tied system by optimizing the operation schedule of different energy sources in a residential complex energy system. The optimization was based on the Invasive Weed Optimization technique (IWO) and the impact of selling and buying to/from the utility grid was considered.

In this paper, storage optimization and cost minimization are based on PSO. A grid-connected PV system with battery is presented with a configuration that allows the PV system owner to either sell or buy energy from the grid depending on the system's output. The paper focuses on sizing the battery energy storage for a typical customer already owning a $5 \mathrm{~kW}$ PV system in order to reduce daily electricity bills. 


\section{SYSTEM MODELING AND PROBLEM FORMULATION}

Mathematical models of various components that are parts of this grid-connected PV system were developed in order to establish an optimal energy flow within the system. This energy flow approach is considered for the modeling process of the system's components for a time step $(\delta t)$ of one hour. The function of battery storage in a grid-tied PV system varies according to its configuration. Some configurations use the direct charging method by charging the battery with PV panels DC voltage. In this paper, a different topology is set up in which the battery, the PV, the Load and the grid are connected to the same AC bus as in Figure 1. The battery is connected to the AC bus through an inverter/charge. The PV DC output is also fed to the AC bus via a three-phase DC/AC converter, which is modeled using a 3-level insulated gate bipolar transistor (IGBT) bridge. B400_2 is a three-phase V-I measurement block serving as the common AC bus interconnecting the sources and the load. The grid is modeled as an AC source and functions as a swing bus to balance the power demands of the household or absorb PV power. Power (positive sequence) block is used to monitor the active power exchange between the grid and PV system and serves for netmetering. An arbitrary household load of $3 \mathrm{~kW}$ has been assumed in order to show how it is connected to the rest of the system.

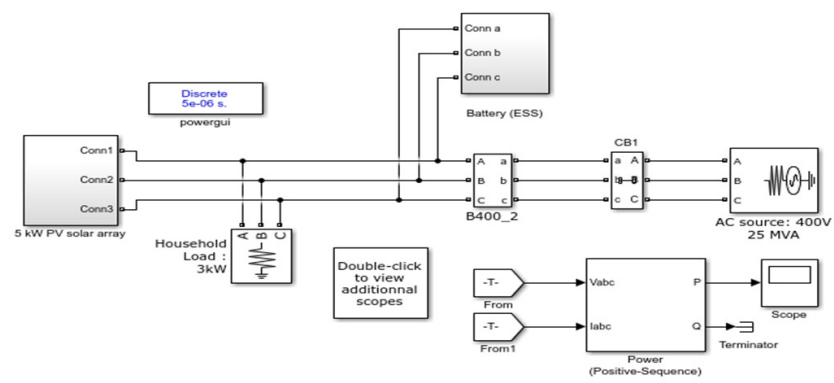

Fig. 1. Simulink model of the grid-connected PV system with battery

An average hourly PV energy production along with the average hourly load consumption for the considered residence has been calculated and plotted in Figure 2. The load energy used for simulation in this paper has a daily average of $12.15 \mathrm{kWh}$ whereas the PV energy output has a daily average of $21.443 \mathrm{kWh}$. This means that only $56.6 \%$ of PV energy is consumed by the load and the rest must be sold to the grid.

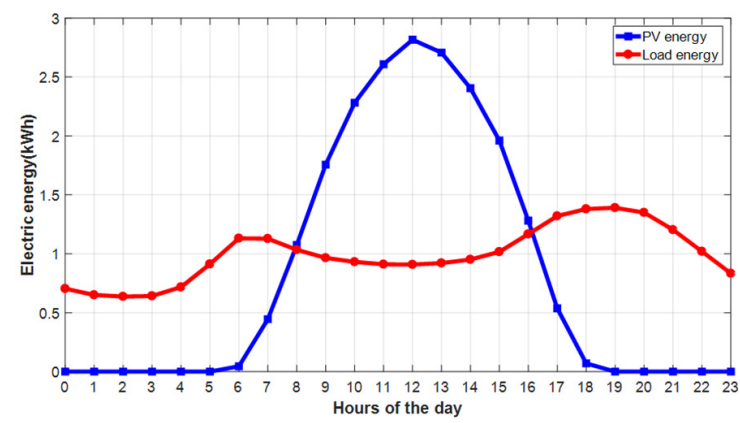

Fig. 2. Average hourly load and PV output throughout 2016

\section{A. Component Modeling and Data Acquisition}

\section{1) PV Array Model}

The performance of the solar panels is highly governed by ambient temperature and solar irradiation. The optimal selection of a PV module with respect to the anticipated functional ambient conditions enhances the module's performance and therefore increases energy production. For this work, a $5 \mathrm{kWp}$ PV array already installed on the top of a garage at Strathmore University was considered.



Fig. 3. Montly PV output power throughout 2016

The PV output is modeled as a linear power with respect to solar radiation $[9,13]$ :

$$
P_{p v}(d, t)=G i \times A \times \eta_{p v}
$$

where $G i$ is the solar radiation at time interval $i, A$ is the PV panel area and $\eta_{p v}$ is the PV efficiency.

The raw output data of the $5 \mathrm{kWp}$ PV array were collected from Strathmore University, Nairobi, Kenya. The collected data were recorded hourly over the whole year of 2016 (Figure $3)$. The module efficiency was taken as $14.91 \%$.

\section{2) Battery Storage}

Capacity fading is normally estimated through real life experimentation by subjecting the battery to different charge/discharge rates, which can be hard and slow. An alternative way is the mathematical model which was developed based on Arrhenius equation in [14]:

$$
C_{\text {loss }}=A \exp \left(\frac{-E_{a}}{R \times T}\right) t^{z}
$$

where $C_{\text {loss }}$ is Capacity loss, $A$ is pre-exponential factor, $E_{a}$ is the processed energy, $R$ and $T$ are the universal gas constant and temperature.

In a practical scenario the battery charge and discharge rates change according to the grid and PV behavior, resulting in an increase of capacity fade with respect to increase in charge/discharge rate, SOC and temperature. The Arrhenius equation of battery capacity fading has been adapted to take into account the charge and discharge rates of the battery. The proposed model depends on nominal capacity $C_{N}$, charge rate $P_{B C}$, discharge rate $P_{B D}$, energy processed for charging $E_{c}$, energy processed for discharging $E_{d}$, the gas constant, and temperature. 


$$
\begin{gathered}
C_{\text {loss }}^{c}=\left[A \exp \left(\frac{-C \times P_{B C} \times E_{c} \times C_{N}}{R \times T}\right)\right]+ \\
{\left[B \exp \left(\frac{-D \times P_{B D} \times E_{d} \times C_{N}}{R \times T}\right)\right]}
\end{gathered}
$$

This model has a particular advantage of being able to determine the capacity fade of the battery subjected to different charge-discharge rates. The various parameters of (3) can be found from the capacity loss data given by the battery manufacturers. The battery investment is taken as $200 \$ / \mathrm{kWh}$ [15] and the battery inverter cost has been estimated at $6006 \$ / \mathrm{kW}[16]$.

\section{3) Grid}

Electricity is expected to either be sold to the grid or purchased from it. For simplicity, we assume that the sellingpurchasing prices are equal at instant time $t$ and we denote them as $E_{\text {Price }}(d, t)$. Consequently, there is an electric power interchange between the utility grid and the PV system denoted by $P_{\text {grid }}(\underline{t})$ such that: $P_{\text {grid }}(t)<0$ when electricity is sold to the utility grid and $P_{\text {grid }}(t)>0$ when electricity is bought from the grid. The system contains costs and benefits where costs account for the purchase of electricity from the grid and benefits account for selling electricity to the grid. The electric power exchange $P_{\text {grid }}(t)$ in combination with the PV output power $P_{p v}(t)$ have to satisfy the power balance requirements as follow:

$$
\begin{gathered}
P_{\text {grid }}(t)+\eta_{p v} P_{p v}(t)=P_{\text {load }}(t)+P_{\text {bus }}(t) \\
P_{\text {grid }}(t)=P_{\text {load }}(t)-\eta_{p v} P_{p v}(t)+P_{\text {bus }}(t)
\end{gathered}
$$

where $P_{b u s}(t)$ is the charging/discharging rate of the battery on the AC bus, and $P_{\text {load }}(t)$ is the load power.

\section{4) Residential Load}

In a residential building, load appliances could have a fixed or a relatively flexible schedule, separating loads categories (lights and TVs from refrigerators and air conditioners). However, the details of load priorities are not analyzed in this work as a residential load profile has been collected from MAISY database and adapted to the Kenyan context. An hourly load profile for a residential building has been collected and plotted in Figure 4.

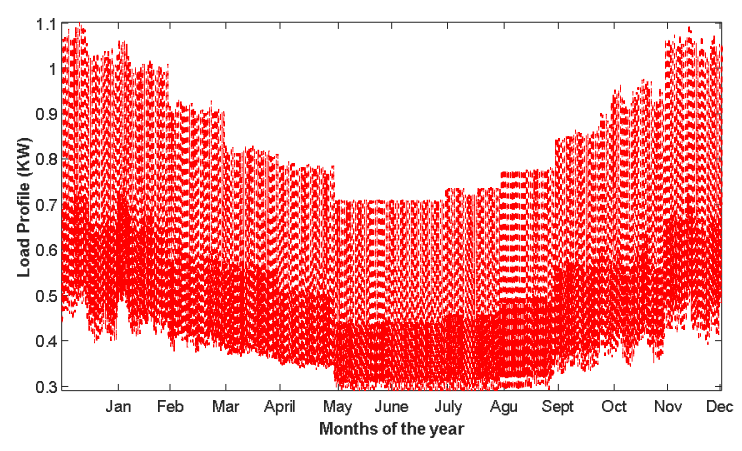

Fig. 4. Residential montly load profile throughout 2016

\section{B. Problem Formulation and Cost Calculation}

The formulated problem is to minimize the sum of the different costs such as the cost of imported power, the cost of battery degradation, and the annualized inverter cost as expressed in (5):

$$
\operatorname{Min} F=\left(\sum_{d=1}^{N} \sum_{t=1}^{h} C_{B C L}(d, t)+E_{C B}(d, t)\right)+A C_{i n v}
$$

where $C_{B C L}$ is the cost of battery capacity loss, $E_{C B}$ is the energy cost and benefit, $A C_{i n v}$ is the annualized battery inverter cost and $d, t$ are day and time respectively.

The PV system is considered as previously installed and its energy is already available to the sample customer. Equation (5) emphasizes on the impact of battery capacity loss and electricity sell/purchase to/from grid on the overall running cost. It captures the effect of only the battery DC/AC inverter through $A C_{i n v}$ (annualized inverter cost). In order to compare the running costs for grid-tied PV with battery storage and gridtied PV without battery storage, PV investment cost, PV $\mathrm{DC} / \mathrm{AC}$ inverter cost, installation, and replacement cost are not considered. The reason is that those four variables are common for both cases.

\section{TABLE I. INPUT PARAMETERS}

\begin{tabular}{|c|c|c|}
\hline Parameter & Value & Unit \\
\hline PV capacity & 5 & $\mathrm{~kW}$ \\
\hline PV efficiency $\eta_{P V}$ & 14.91 & $\%$ \\
\hline Battery investment cost & 200 & $\$ / \mathrm{kWh}$ \\
\hline State of charge $\left(S O C_{\min , \max }\right)$ & 30 and 90 & $\%$ \\
\hline Aging coefficient $(z)$ & $3 \times 10^{-4}$ & $\mathrm{n} / \mathrm{a}$ \\
\hline Nominal charging rate & 10 & $\mathrm{hrs}$ \\
\hline Self-discharging factor $(a)$ & 0.0000347 & $\mathrm{n} / \mathrm{a}$ \\
\hline PV inverter efficiency $\eta_{\text {inv }}$ & 97 & $\%$ \\
\hline Bat. inverter efficiency $\eta_{\text {bat }}$ & 94 & $\%$ \\
\hline Sampling time interval $\left(\delta_{t}\right)$ & 1 & $\mathrm{hr}$ \\
\hline Annual real interest rate $(i)$ & 4 & $\%$ \\
\hline Battery charge/discharge eff. $\eta_{c h} / \eta_{\text {disch }}$ & 90 & $\%$ \\
\hline Electricity charges & 0.1583 off-peak & $\$$ \\
\hline
\end{tabular}

The cost of the battery capacity fade for a given hour of the system operation is expressed as [6]:

$$
C_{B C L}(d, t)=\frac{B_{C L}(d, t) \times B_{\text {invest }- \text { cost }}}{1-S O H_{\text {min }}}
$$

where $B_{C L}(d, t)$ is the battery capacity loss on day $d$ at time $t$, $B_{\text {invest-cost }}$ is the battery investment cost and $S O H_{\min }$ is the battery minimum state of health.

The battery has the following dynamic equation [17]:

$$
\frac{d E_{B}(d, t)}{d t}=P_{B}(d, t)
$$

where $P_{B}$ is the battery energy and $P_{B}(d, t)>0$ during battery charging state, $P_{B}(d, t)<0$ during battery discharging state, and $P_{B}(d, t)=0$ during battery inactive state.

In order to take into account the battery aging effect, a battery usable capacity is considered after each sampling time and denoted as $C(t)$. Obviously, at initial time $t_{0}$ the usable battery capacity is same as the battery nominal capacity $C_{n}$. Then $C\left(t_{0}\right)=C_{n}$. The above defined usable battery capacity is 
updated at every sampling interval by subtracting a cumulative battery capacity loss $C_{B \text { loss }}(d, t)$ from the battery nominal capacity as shown in (8):

$$
\begin{gathered}
C(d, t)=C_{n}-C_{B \text { loss }}(d, t) \\
C_{\text {Bloss }}\left(t_{0}\right)=0
\end{gathered}
$$

Therefore, the battery capacity loss on day $d$ at time $t$ can be expressed as:

$$
B_{C L}(d, t)=C_{B l o s s}(d, t)-C_{B l o s s}(d, t-\delta t)(9)
$$

The model of the battery aging is [18]:

$$
\frac{d C_{B l o s s}(d, t)}{d t}=\left\{\begin{array}{c}
-Z \times P_{B}(d, t), \quad \text { if } P_{B}(d, t)<0 \\
0 \quad \text { otherwise }
\end{array}\right.
$$

Using the conventional efficiency of the battery $\eta_{B}$ and the sampling interval $\delta t$, the above relation becomes:

$$
C_{B l o s s}(d, t)=\left\{\begin{array}{c}
C_{B l o s s}(d, t-\delta t) \frac{-Z \times P_{B}(d, t) \times \delta t}{\eta_{B}} \text { if } P_{B}<0 \\
C_{B l o s s}(d, t-\delta t) \text { otherwise }
\end{array}\right.
$$

where $Z$ is the battery aging coefficient.

This expression simply indicates that for the battery-aging model, capacity loss is encountered only in the discharge process. Thus, we can see that in $(9), B_{C L}(d, t)$ is equal to zero when the battery is charging. Therefore, the calculation of cost of battery capacity loss in (6) entirely depends on the state of the battery, which is either charging or discharging. The battery state of charge is updated after each sampling period as:

$$
\begin{aligned}
& \operatorname{SOC}(d, t)=\operatorname{SOC}(d, t-\delta t)(1-a)+\eta_{c h} \frac{P_{B}(d, t)}{C(d, t) \times V} \delta t \\
& \operatorname{SOC}(d, t)=\operatorname{SOC}(d, t-\delta t)(1-a)+\eta_{\text {disch }} \frac{P_{B}(d, t)}{C(d, t) \times V} \delta t
\end{aligned}
$$

Equation (12a) is for battery charging and (12b) for discharging. $C(d, t)$ is the usable battery capacity.

Since the system allows purchasing and selling electricity from and to the utility grid, its operation contains both cots and benefits for the system owner that are combined and denoted together as $E_{C B}$. Costs account for energy bought from and benefits account for energy sold to the utility grid. Equation (13) describes the mathematical expression of the cost of the energy exchanged:

$$
E_{C B}(d, t)=E_{\text {Price }}(d, t) \times P_{\text {grid }}(d, t) \delta t
$$

Considering the two different scenarios that result from the reading on the net-meter, the above equation can be extended to account for the net power readings. It can be expressed as:

$$
\begin{aligned}
E_{C B}(d, t)= & \left\{\left[E_{\text {price }}(d, t) \times P_{\text {Net } 1}(d, t)+\right.\right. \\
& {\left.\left[E_{\text {price }}(d, t) \times P_{\text {Net } 2}(d, t)\right]\right\} \delta t }
\end{aligned}
$$

where $P_{\text {Net } 1}(d, t)>0$ corresponds to the cost of buying power from the grid and $P_{N e t 2}(d, t)<0$ corresponds to expected benefits for selling excess power to the grid.

$$
\begin{aligned}
& C=\left(\sum_{d=1}^{N} \sum_{t=1}^{h} E_{\text {price }}(d, t) \times P_{\text {grid }}^{\text {import }}(d, t)\right) \\
& B=\left(\sum_{d=1}^{N} \sum_{t=1}^{h} E_{\text {price }}(d, t) \times P_{\text {grid }}^{\text {export }}(d, t)\right)
\end{aligned}
$$

where $P_{\text {grid }}^{\text {import }}$ is the imported power from the grid and $P_{\text {grid }}^{\text {export }}$ is the power exported to the grid.

The capital recovery factor and the annualized battery cost can be calculated by (17) and (18) respectively:

$$
\text { Battery Capital Recovery Factor }(C R F)=\frac{i(1+i)^{N}}{(1+i)^{N}-1}
$$

where $i$ is the annual interest rate and $N$ is the battery lifetime, and

$$
\text { annualized battery cost }=B_{\text {invest }- \text { cost }} \times C R F
$$

For easier calculations it is assumed that the prices for sales and purchases are identical. The system is subjected to a number of operational constraints:

$$
\begin{gathered}
E_{B \min } \leq E_{B}(d, t) \\
0 \leq E_{B}(d, t) \leq C(d, t) \\
S O C_{\min } \leq S O C(t) \leq S O C_{\max } \\
S O H(t) \geq S O H_{\text {min }}
\end{gathered}
$$

The total annual operation cost is therefore calculated as:

$$
\begin{aligned}
\text { An.op. } \cos t & =\left(\sum_{d=1}^{365} \sum_{t=1}^{24} C_{B C L}+E_{C B}(d t)\right) \\
& +A C_{i n v}
\end{aligned}
$$

The lifetime of the battery is calculated in (21):

$$
\text { Battery lifespan }(N)=\frac{C_{n} \times V}{C_{B l o s s-y e a r}}
$$

where $C_{B l o s s-y e a r}$ is the annual additive battery capacity loss.

\section{PARTICLE SWARM OPTIMIZATION ALGORITHM}

Particle swarm optimization is used to solve this optimization problem. The algorithm initializes the particles to search the best solution in the entire search space from the objective function [19]. In this study, the swarm is initialized as $i=1$ : nPop where nPop is the swarm size, taken as 30 particles. The particles refer to different random battery sizes from 100 to $3000 \mathrm{Ah}$. The number of iterations is set to a maximum of 20 and initialized as $j=1$ : MaxIt where MaxIt is the maximum number of iterations. The inertia maximum and minimum weight is set to 0.9 and 0.2 respectively. The acceleration coefficients are assumed as 2 . Each particle is set to an initial zero velocity and for every particle (random battery size) the objective function is executed to compare the costs. Each particle compares the target value with the best particle's value, if the target value is lower, sets this value, and records the location of the corresponding particle [20]. Velocities and positions are updated after each iteration [21]. Each battery capacity has a position and each position has a velocity. The velocity of the $k$-th is updated by:

$$
v_{k, \text { new }}^{j}=w v_{k, \text { old }}^{j}+c_{1} r_{1}\left(x_{k, \text { pbest }}^{j}-x_{k}^{j}\right)+c_{2} r_{2}
$$

where $v_{k, \text { new }}^{j}$ is the new velocity of the $k$-th particle at the $j$-th iteration, $w$ is the inertia weight, $v_{k, \text { old }}^{j}$ is the old velocity of the $k$-th particle at the $j$-th iteration, $c_{1}$ and $c_{2}$ are the acceleration 
constants, $r_{1}$ and $r_{2}$ are two random numbers in $[0,1]$. The position of the the $k$-th is updated using (23):

$$
x_{k, \text { new }}^{j}=x_{k, \text { old }}^{j-1}+v_{k, \text { new }}^{j}
$$

where $x_{k \text {,old }}^{j-1}$ is the old position of the $k$-th particle at the previous iteration.

In this study, the position $X$ is the size and the velocity is the corresponding running cost. The objective function is to minimize the total operating cost $F$. The personal best of each battery is its size and the resulting operating cost. Therefore, for every iteration, there is a corresponding battery size which, when integrated in this grid-connected PV system results in a minimum operating cost which is the global best.

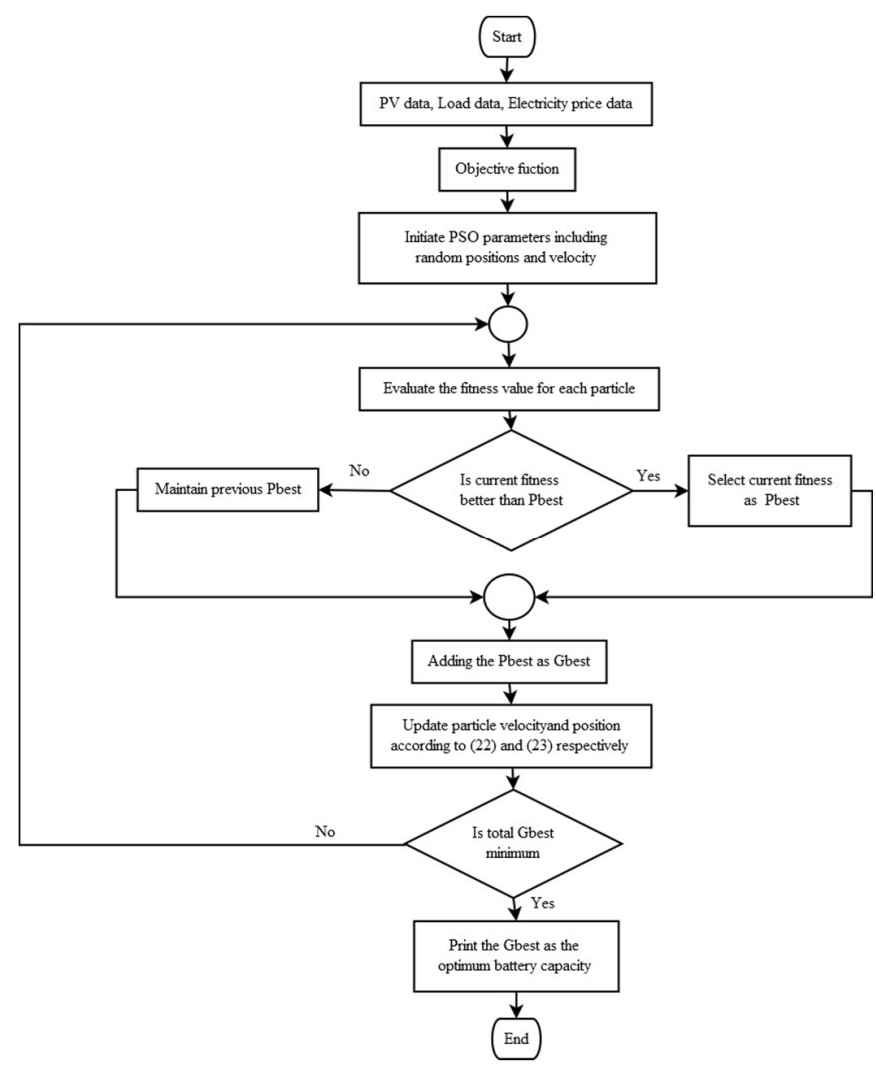

Fig. 5. Flow chart of the proposed PSO algorithm

\section{RESULTS AND DISCUSSION}

In this simulation, the optimization algorithm computes the optimized battery size, the corresponding operation cost of the system, the additive battery degradation or capacity loss, and the battery lifespan. These different values are generated and compared with respect to two scenarios: A grid-connected system with and without battery energy storage. In both cases, we have distinguished import and export energies as $P_{\text {grid }}>0$ and $P_{\text {grid }}<0$ respectively. Similarly, the battery charged and discharged energies are distinguished as $P_{B} d c>0$ and $P_{B} d c<0$ respectively. This is because the net-metering system needs to calculate the net power.

\section{A. Grid-connected with Battery Energy Storage}

In this PSO-based optimization, a set of adequate numerical quantities for the PSO parameters were chosen to get the algorithm quicker and faster. The population size was set to 30 , the maximum number of iterations was set to $20, c_{1}$ and $c_{2}$ were set to 2 and wdamp to 0.99 .

After initializing the parameters, the PSO algorithm was utilized to compute the optimum battery size with respect to cost as depicted in Figure 6. The dots represent the fitness values (total cost for a given battery capacity) and each of them represents a potential solution. According to Figure 6(a), we can realize that a few points are close to the optimal battery size and could be mistaken as the best solution. This has been avoided by magnifying the bottom part of the figure and narrowing the search space to $1000-1600 \mathrm{Ah}$ to highlight the final solution or the optimal battery size as 1200Ah in Figure $6(\mathrm{~b})$. This optimal size is equivalent to $14.4 \mathrm{kWh}$ with a corresponding total annual cost or an annual income of $449.42 \$$ to the PV system owner paid by the utility. The negative sign simply indicates that the exported energy to the grid was higher than the imported energy from the grid resulting in a benefit to the system owner. The capital cost of the $14.4 \mathrm{kWh}$ battery is calculated as $2880 \$$ at a rate of $200 \$ / \mathrm{kWh}$. The battery lifespan is calculated by (21) as 13.5 years and the battery recovery factor is found as 0.100143 by (17). The annualized battery cost or real battery capacity loss cost is then estimated as $288.4 \$$ using the expression in (18).



(a)

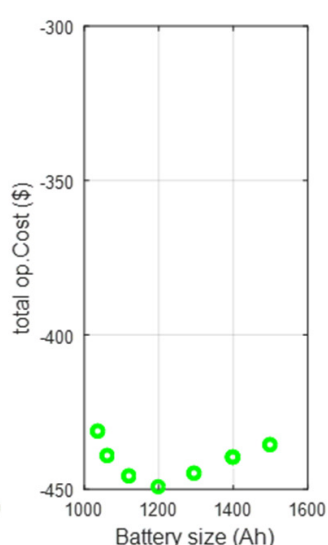

(b)
Fig. 6. Optimal battery capacity with respect to cost

Figure 7 shows the optimal energy flow within the system when a $14.4 \mathrm{kWh}$ battery storage is installed. The plots are for one sample day of the year $\left(53^{\text {rd }}\right)$ and we can realize that the load demand entirely depends on the grid during off-peak hours (00:00 to 7:00). PV power starts to be available after 7:00 and the peak production of $4.047 \mathrm{~kW}$ is recorded at 13:00. The load takes only $0.799376 \mathrm{~kW}$ out of $4.047 \mathrm{~kW}$ and the excess $3.2476 \mathrm{~kW}$ is fed to the grid to make profit. 


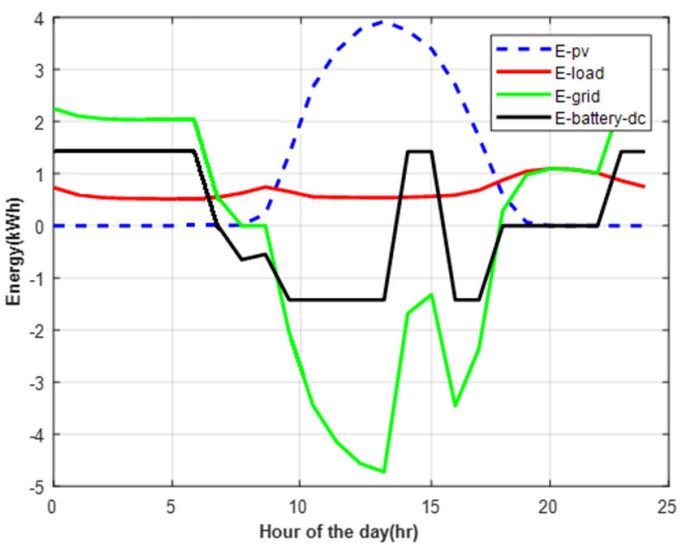

Fig. 7. Optimal energy flow schedule for one day

Figure 8 illustrates how the energy varies in the battery and how the algorithm handles the constraint of SOC boundaries. According to this figure, battery discharges its energy to the utility grid from 8:00 until its state of charge reaches its minimum. The battery is kept inactive for one hour (13:00 to 14:00) then starts charging from PV until 16:00. The battery releases its energy to the utility grid again until its minimum SOC. From 18:00 to $22: 00$, the load is mostly relying on the grid and the battery is kept inactive. Finally, during off-peak hours (22:00 forwards), the battery charges from the utility grid. We realize that the algorithm only discharges the battery at points where it is advantageous.

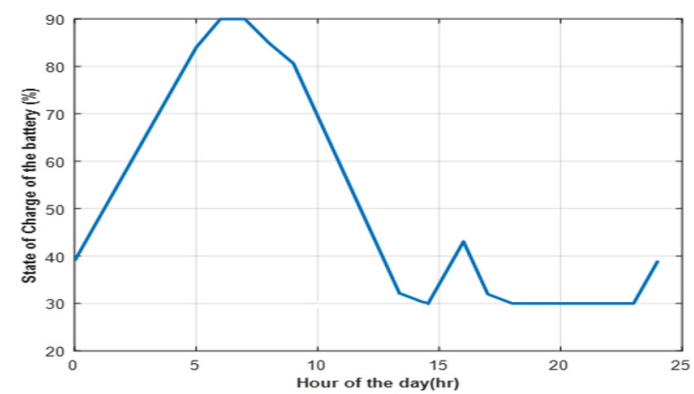

Fig. 8. SOC variation of the battery during one regular day

In Figure 9, it can be seen that during the sampled day the additive battery capacity loss of this grid-connected PV-battery system increases during discharging time due to the aging effect described in (11). The additive battery capacity loss is $0.167318 \mathrm{kWh}$ at the start of the day and ends at $0.170278 \mathrm{kWh}$ totaling a daily additive battery capacity loss of $0.00296 \mathrm{kWh}$ or $2.96 \mathrm{Wh}$. The Figure shows that the battery degradation increases only during discharge state from 8:00 to $13: 00$ and from 16:00 to 18:00. Figure 10 reflects the convergence of the proposed PSO algorithm to find the optimal solution for four independent runs with respect to costs. As depicted in this Figure, optimal battery size is reached after about 10 iterations and the optimum solution converges to the same global best for the four runs. If the load demand is increased by $10 \%$ for each of the 8760 hours, the results show that the optimal battery capacity remains the same but the battery lifetime decreases by $3.7 \%$. A change of $21 \%$ in the annual income is also recorded.
If the load is decreased by the same percentage, the same proportions apply in favor of the owner. On the other hand, if the energy consumption is kept constant and the hourly power profile is decreased by $5 \%$, the results show that the optimal battery capacity changes from $1200 \mathrm{Ah}$ to $1100 \mathrm{Ah}$ and the annual income of the PV system owner decreases by $24 \%$.

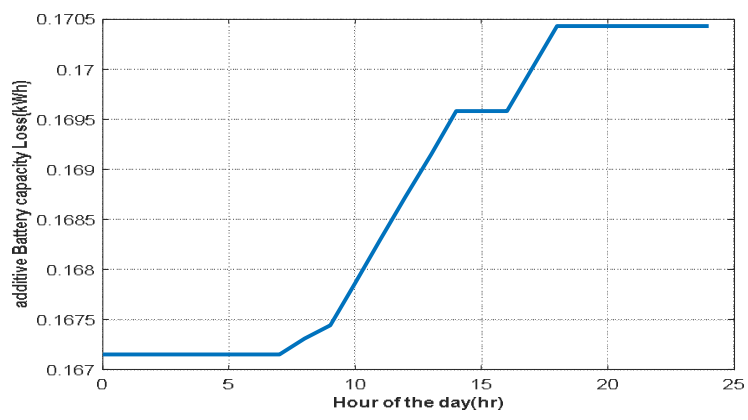

Fig. 9. Additive battery capacity loss during one day

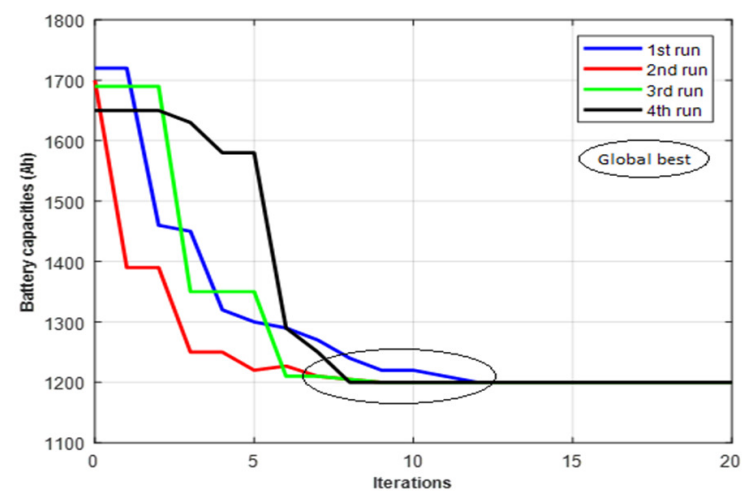

Fig. 10. Convergence of the PSO for four independent runs

\section{B. Grid-connected without Battery Energy Storage}

If the system has no energy storage, the utility grid acts as both energy storage and energy source. During peak production, the energy surplus is injected to the utility grid. The system starts feeding energy to the grid immediately after the production exceeds load demand. During nights, cloudy days, or power cuts, the utility grid performs as an energy source to cover the load.



Fig. 11. Energy flow for a typical day of the year 
In Figure 11, it can be seen that during the hours when the PV was unavailable, the load entirely relied on the grid. PV starts generating from 7:00, however, its energy is not enough to fully supply the load before 9:00. During this period, the grid continues to supply energy. Between 9:00 and 17:00, PV energy exceeds the load demand and the excess is injected to the grid. According to the Figure, out of $4.047 \mathrm{~kW}$ of peak production recorded at 13:00, only $0.79937 \mathrm{~kW}$ were consumed by the load and the excessive $3.2476 \mathrm{~kW}$ were sold to the grid. From 19:00 and onwards the load is entirely covered by the grid. The optimization algorithm returned an annual benefit of $210.4384 \$$ in favor of the system owner since only annual electricity cost and benefits are the costs involved in this type of configuration.

\section{CONCLUSION}

The current paper presented a PSO method for optimally sizing the energy storage of a grid-connected residential PV system. While satisfying a set of operation and optimization constraints, the goal was two-fold: to lower the amount of power import from the grid and to minimize the cost of battery degradation caused by the aging effect. The goals were achieved through optimally scheduling the battery operation. Simulations were carried out for a system with battery storage and a system without battery storage. The results showed that electricity charges from utility and battery degradation costs highly influence the optimal battery capacity determination in a grid-tied PV system. Results demonstrated that upon efficiently and optimally scheduling the battery operation, electricity bills can be significantly minimized. The system without battery returns lower benefits and its entire dependency on the utility grid during nights and cloudy days makes it less desirable.

\section{DATA AVAILABILITY}

The raw data used to get the results in this paper can be provided upon request.

\section{ACKNOWLEDGMENT}

The authors acknowledge the African Union (AU) for funding this research through The Pan African University.

\section{REFERENCES}

[1] Y. Ru, J. Kleissl, S. Martinez, "Storage size determination for gridconnected photovoltaic systems", IEEE Transactions on Sustainable Energy, Vol. 4, No. 1, pp. 68-81, 2013

[2] D. Abdoulaye, Z. Koalaga, F. Zougmore, "Grid-connected photovoltaic (PV) systems with batteries storage as solution to electrical grid outages in Burkina Faso", 1st International Symposium on Electrical Arc and Thermal Plasmas in Africa, Ouagadougou, Burkina Faso, October 17-21, 2012

[3] Y. Riffonneau, S. Bacha, F. Barruel, S. Ploix, "Optimal power flow management for grid connected PV systems with batteries", IEEE Transactions on Sustainable Energy, Vol. 2, No. 3, pp. 309-320, 2011

[4] Y. Choi, H. Kim, "Optimal scheduling of energy storage system for selfsustainable base station operation considering battery wear-out cost", Eighth International Conference on Ubiquitous and Future Networks, Vienna, Austria, July 5-8, 2016

[5] S. Grillo, A. Pievatolo, E. Tironi, "Optimal storage scheduling using Markov decision processes", IEEE Transactions on Sustainable Energy, Vol. 7, No. 2, pp. 755-764, 2016
[6] M. Gitizadeh, H. Fakharzadegan, "Battery capacity determination with respect to optimized energy dispatch schedule in grid-connected photovoltaic (PV) systems", Energy, Vol. 65, pp. 665-674, 2014

[7] F. Mavromatakis, G. Viskadouros, G. Xanthos, "Photovoltaic systems and net metering in Greece", Engineering, Technology \& Applied Science Research, Vol. 8, No. 4, pp. 3168-3171, 2018

[8] J. Li, "Optimal sizing of grid-connected photovoltaic battery systems for residential houses in Australia”, Renewable Energy, Vol. 136, pp. 12451254, 2019

[9] M. A. Mohamed, A. M. Eltamaly, A. I. Alolah, "PSO-based smart grid application for sizing and optimization of hybrid renewable energy systems", PLoS One, Vol. 11, No. 8, pp. 1-22, 2016

[10] L. A. Wong, H. Shareef, A. Mohamed, A. A. Ibrahim, "Optimal placement and sizing of energy storage system in distribution network with photovoltaic based distributed generation using improved firefly algorithms", World Academy of Science, Engineering and Technology, International Journal of Electrical, Computer, Energetic, Electronic and Communication Engineering, Vol. 11, No. 7, pp. 864-872, 2017

[11] M. O. Badawy, F. Cingoz, Y. Sozer, "Battery storage sizing for a grid tied PV system based on operating cost minimization", IEEE Energy Conversion Congress and Exposition, Milwaukee, USA, September 1822, 2016

[12] V. S. Borra, K. Debnath, "Comparison between the dynamic programming and Particle Swarm Optimization for solving unit commitment problems", IEEE Jordan International Joint Conference on Electrical Engineering and Information Technology, Amman, Jordan, April 9-11, 2019

[13] P. Ahmadi, M. H. Nazari, S. H. Hosseinian, "Optimal resources planning of residential complex energy system in a day-ahead market based on Invasive Weed Optimization algorithm", Engineering, Technology \& Applied Science Research, Vol. 7, No. 5, pp. 1934-1939, 2017

[14] K. Thirugnanam, H. Saini, P. Kumar, "Mathematical modeling of Li-Ion battery for charge/discharge rate and capacity fading characteristics using Genetic Algorithm approach”, IEEE Transportation Electrification Conference and Expo, Dearborn, USA, June 18-20, 2012

[15] D. T. Ton, C. J. Hanley, G. H. Peek, J. D. Boyes, Solar energy grid Integration Systems: Energy Storage (SEGIS-ES), Sandia National Laboratories, 2008

[16] E. McKenna, M. McManus, S. Cooper, M. Thomson, "Economic and environmental impact of lead-acid batteries in grid-connected domestic PV systems", Applied Energy, Vol. 104, pp. 239-249, 2013

[17] P. Mohanty, K. R. Sharma, M. Gujar, M. Kolhe, A. N. Azmi, "PV system design for off-grid applications", in: Solar photovoltaic system applications: A guidebook for off-frid electrification, Springer, 2015

[18] Y. Riffonneau, S. Bacha, F. Barruel, S. Ploix, "Optimal power flow management for grid connected PV systems with batteries", IEEE Transactions on Sustainable Energy, Vol. 2, No. 3, pp. 309-320, 2011

[19] L. Ravi, C. V. Kumar, M. R. Babu, "Stochastic optimal management of renewable microgrid using simplified Particle Swarm Optimization algorithm", 4th International Conference on Electrical Energy Systems, Chennai, India, February 7-9, 2018

[20] K. Yenchamchalit, Y. Kongjeen, K. Bhumkittipich, N. Mithulananthan, "Optimal sizing and location of the charging station for plug-in electric vehicles using the Particle Swarm Optimization technique", International Electrical Engineering Congress, Krabi, Thailand, March 7-9, 2018

[21] D. Truong, "Hybrid PSO-optimized ANFIS-based model to improve dynamic voltage stability", Engineering, Technology \& Applied Science Research, Vol. 9, No. 4, pp. 4384-4388, 2019 